\title{
OPEN Dereplication of antimicrobial biosurfactants from marine bacteria using molecular networking
}

\begin{abstract}
Albert D. Patiño ${ }^{1}$, Manuela Montoya-Giraldo ${ }^{1}$, Marynes Quintero $^{1}$, Lizbeth L. López-Parra ${ }^{2}$, Lina M. Blandón ${ }^{1 \bowtie}$ \& Javier Gómez-León ${ }^{1}$

Biosurfactants are amphiphilic surface-active molecules of microbial origin principally produced by hydrocarbon-degrading bacteria; in addition to the bioremediation properties, they can also present antimicrobial activity. The present study highlights the chemical characterization and the antimicrobial activities of biosurfactants produced by deep-sea marine bacteria from the genera Halomonas, Bacillus, Streptomyces, and Pseudomonas. The biosurfactants were extracted and chemically characterized through Chromatography TLC, FT-IR, LC/ESI-MS/MS, and a metabolic analysis was done through molecular networking. Six biosurfactants were identified by dereplication tools from GNPS and some surfactin isoforms were identified by molecular networking. The halfmaximal inhibitory concentration (IC $\mathrm{C}_{50}$ ) of biosurfactant from Halomonas sp. INV PRT125 (7.27 mg $\left.\mathrm{L}^{-1}\right)$ and Halomonas sp. INV PRT124 $\left(8.92 \mathrm{mg} \mathrm{L}^{-1}\right)$ were most effective against the pathogenic yeast Candida albicans ATCC 10231. For Methicillin-resistant Staphylococcus aureus ATCC 43300, the biosurfactant from Bacillus sp. INV FIR48 was the most effective with IC 50 values of $25.65 \mathrm{mg} \mathrm{L}^{-1}$ and $21.54 \mathrm{mg} \mathrm{L}^{-1}$ for $C$. albicans, without hemolytic effect $(<1 \%)$, and non-ecotoxic effect in brine shrimp larvae (Artemia franciscana), with values under $150 \mathrm{mg} \mathrm{L}^{-1}$, being a biosurfactant promising for further study. The extreme environments as deep-sea can be an important source for the isolation of new biosurfactants-producing microorganisms with environmental and pharmaceutical use.
\end{abstract}

The marine ecosystem is an important source of compounds with interesting biological activities that can be given economic or industrial value. In tropical countries like Colombia that has a great diversity of unexplored natural resources, especially the deep-sea habitats that could host a variety of microbial species have not yet been described ${ }^{1}$.

Deep-sea microorganisms in the Colombian Caribbean Sea have been little explored, and it is generally unknown what metabolites they can produce. It is possible to infer that, due to living in extreme conditions such as high pressure and salinity, shortages of light and nutrients, they have the ability to produce compounds that degrade complex carbon sources such as biosurfactants and chemical defense compounds like antimicrobials ${ }^{2}$.

Currently, microbial resistance is a serious health problem that affects humans ${ }^{3}$. It is estimated that $70 \%$ of pathogenic bacteria are resistant to at least one antibiotic. As consequence, the treatments are ineffective, and the infections are persistent. In addition, inappropriate behaviors like self-prescription facilitates the selection, persistence and dissemination of resistant microorganisms ${ }^{4}$. Therefore, it is necessary to search for new compounds with antimicrobial activity.

Once a bacterium is identified as a possible antimicrobial metabolite producer, the next step is the identification of the compound or groups of compounds responsible for the biological activity. The discovery and elucidation of the structure of these compounds involve several purification steps from the microbial culture. On the other hand, sometimes these metabolites are known because other microbes or organisms produce the same compounds or compounds with similar structural characteristics as in the case of the biosurfactants. In this sense, to facilitate this type of investigations, the data science focused on metabolites has emerged as metabolomics ${ }^{5}$.

\footnotetext{
${ }^{1}$ Marine Bioprospecting Line, Marine and Coastal Research Institute "José Benito Vives de Andréis"-INVEMAR, Calle 25 No. 2-55, Playa Salguero, Santa Marta D.T.C.H., Santa Marta, Colombia. ${ }^{2}$ Grupo de Investigación en Electroquímica y Medio Ambiente (GIEMA), Universidad Santiago de Cali, Calle 5 \# 62-00, Santiago de Cali, Valle del Cauca, Colombia. ${ }^{\square}$ email: Imblando@unal.edu.co
} 


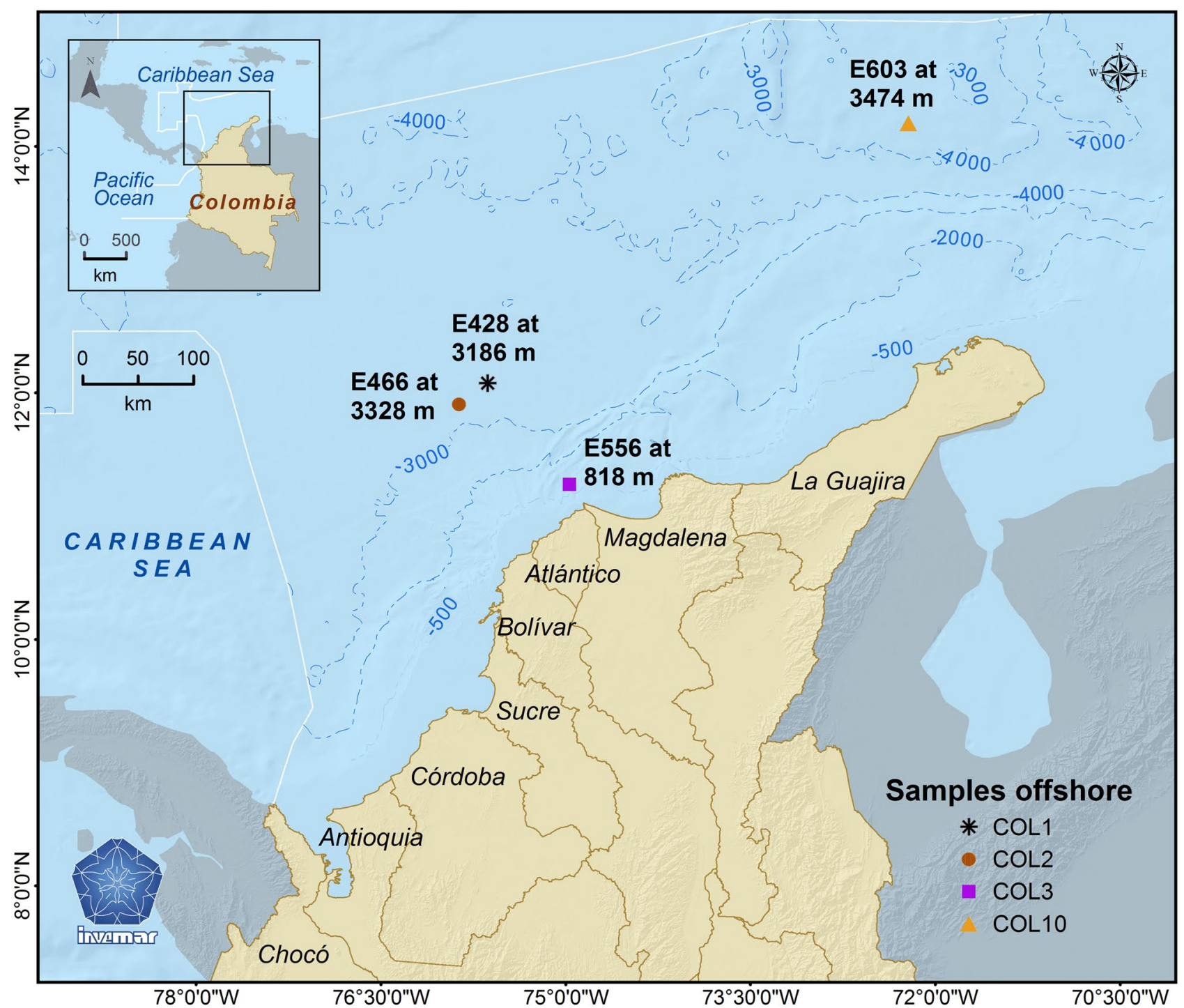

Figure 1. Exploration blocks in Colombian Caribbean Sea, denominated COL1 $\left(12^{\circ} 4{ }^{\prime} 51,30^{\prime \prime} \mathrm{N}\right.$; $\left.75^{\circ} 37^{\prime} 46,60^{\prime \prime} \mathrm{W}\right)$, COL2 (1 $\left.{ }^{\circ} 54^{\prime} 28,40^{\prime \prime} \mathrm{N} ; 75^{\circ} 51^{\prime} 45,20^{\prime \prime} \mathrm{W}\right)$, COL3 (11 $\left.15^{\prime} 28.54^{\prime \prime} \mathrm{N} ; 74^{\circ} 57^{\prime} 56.25^{\prime \prime} \mathrm{W}\right)$ and COL10 $\left(14^{\circ} 11^{\prime} 23.76^{\prime \prime} \mathrm{N} ; 72^{\circ} 13^{\prime} 2.81^{\prime \prime} \mathrm{W}\right)$. " Map created in the Information Services Laboratory (LABSIS in Spanish) at Marine and Coastal Research Institute "José Benito Vives de Andréis"-INVEMAR, with the software ArcGIS 10.8 .

Metabolomics is defined as the comprehensive analysis of metabolites in a biological specimen, combining high-throughput analytical chemistry and multivariate data analysis. It is based on experiments of chemical identification like nuclear magnetic resonance (NMR) and mass spectrometry (MS) analysis ${ }^{6}$. Metabolomics tools like molecular networking, are novel and agile for the identification of the compounds present in a mixture such as microbial culture media. In this sense, the information contributed by MS follows the design of molecular networking facilitating its identification as a procedure known like dereplication ${ }^{7}$.

The aims of this study were to identify the deep-sea bacteria as potential biosurfactant producers. To obtain extracts rich in biosurfactants, to characterize them chemically using thin-layer chromatography (TLC), infrared spectroscopy, chromatography coupled to mass spectrometry (HPLC-MS), and to know the relationship of the metabolic profile into each producer bacteria employing molecular networking. Besides, the antimicrobial activity of the biosurfactants was evaluated against human pathogens such as Methicillin-resistant Staphylococcus aureus subsp. aureus (MRSA) ATCC 43300 and Candida albicans ATCC 10231.

\section{Results}

Selection of biosurfactant producing bacteria: screening of oil-spread. Three hundred seventyeight microorganisms were isolated from sediment samples taken from four different sectors of the Colombian Caribbean Deep-Sea (Fig. 1), they were of diverse depths: 818, 3186, 3328, and $3474 \mathrm{~m}$. The strains were cultivated on Bushnell-Haas/Diesel fuel (DF) broth and sugar cane molasses before making the oil spread test. Finally, five bacteria were selected to continue with the molecular networking studies based on their morphological variety, and their capability to spread crude oil was the selection criteria (Table 1). 


\begin{tabular}{|l|l|l|l|l|l|}
\hline No. catalogue MMNHC & Accesion code GenBank & Sampling station & Strain & OS in DF $(\mathbf{m m})$ & OS in SM $(\mathbf{m m})$ \\
\hline INV PRT124 & MK129413 & E603 at $3474 \mathrm{~m}$ & Halomonas sp. & $5.3 \pm 0.4$ & $6.0 \pm 1.4$ \\
\hline INV PRT125 & MK129414 & E603 at 3474 m & Halomonas sp. & $3.0 \pm 0.0$ & $6.3 \pm 0.6$ \\
\hline INV FIR48 & MK129309 & E428 at 3186 m & Bacillus sp. & $3.3 \pm 0.4$ & $5.3 \pm 0.3$ \\
\hline INV PRT82 & MK129375 & E466 at 3328 m & Pseudomonas sp. & $5.0 \pm 0.0$ & $3.7 \pm 0.6$ \\
\hline INV ACT15 & MK129407 & E556 at $818 \mathrm{~m}$ & Streptomyces sp. & $2.5 \pm 0.7$ & $2.0 \pm 0.4$ \\
\hline
\end{tabular}

Table 1. Oil-spread results of five different deep-sea microorganisms, displacement of crude oil from biosurfactants produced in two carbon sources, diesel fuel (DF) and sugarcane molasses (SM). Media \pm 1 SD of three repetitions.

\begin{tabular}{|l|l|l|}
\hline No & No. catalogue MMNHC & Amount $\mathbf{~ m ~ L ~ L ~}^{-\mathbf{1}}$ \\
\hline 1 & Halomonas sp. INV PRT124 & $12.3 \pm 0.8$ \\
\hline 2 & Halomonas sp. INV PRT125 & $42.0 \pm 1.6$ \\
\hline 3 & Bacillus sp. INV FIR48 & $96.5 \pm 1.4$ \\
\hline 4 & Pseudomonas sp. INV PRT82 & $45.1 \pm 2.2$ \\
\hline 5 & Streptomyces sp. INV ACT15 & $42.8 \pm 3.2$ \\
\hline
\end{tabular}

Table 2. Amount of biosurfactants produced from Halomonas sp. INV PRT124, Halomonas sp. INV PRT125, Bacillus sp. INV FIR48, Pseudomonas sp. INV PRT82 and Streptomyces sp. INV ACT15. Media \pm 1 SD of three repetitions.
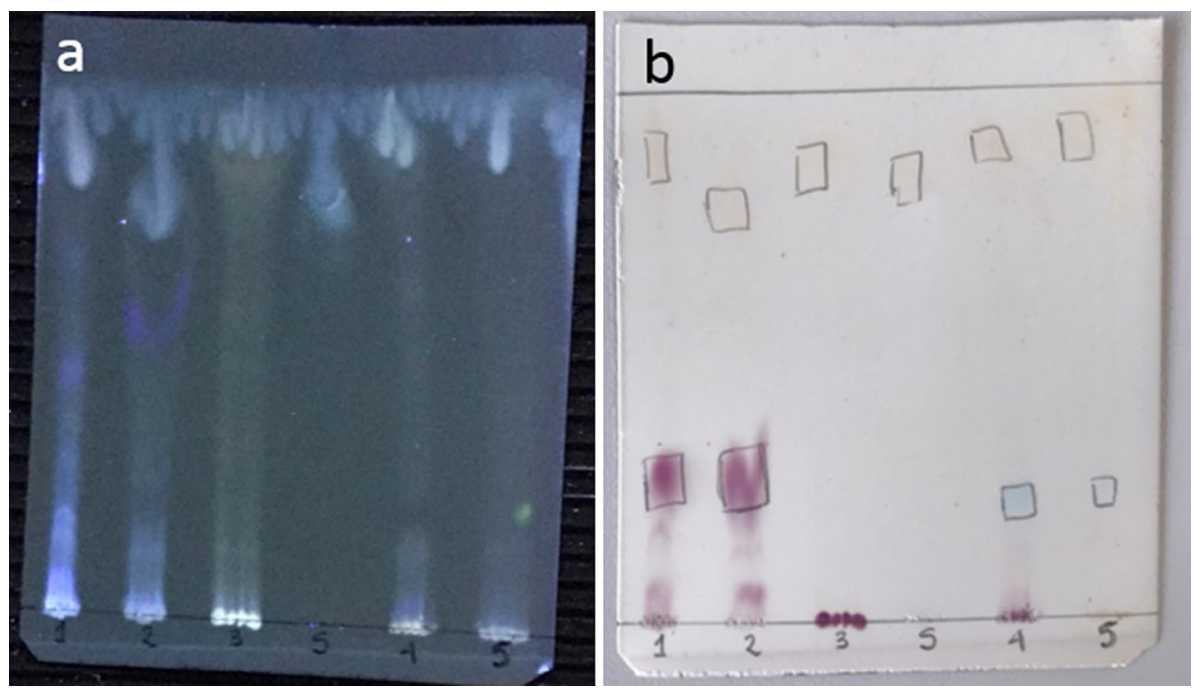

Figure 2. Chromatography thin layer of biosurfactant extracts (1) Halomonas sp. INV PRT124, (2) Halomonas sp. INV PRT125, (3) Bacillus sp. INV FIR48, surfactin (S), (4) Pseudomonas sp. INV PRT82 and (5) Streptomyces sp. INV ACT15. (a) Revealed UV-366 nm, (b) revealed with ninhydrin solution to $0.5 \%$ methanol.

Biosurfactant extraction performance and analyze by TLC. The five bacteria were cultured for seven days, and the biosurfactants (BS) were obtained from liquid ferment cell-free. The BS had an oily appearance and different colors (Figure S4); the production of BS obtained is showed in the Table 2.

The strain with the higher production of BS $\left(96.5 \mathrm{mg} \mathrm{L}^{-1}\right)$ was Bacillus sp. INV FIR48 this result is related to oil-spreading test that gets a halo of $5 \mathrm{~mm}$, one of the highest of our tested strains (Table 1).

The BS have different colors; this could hypothesize that each extract has a different metabolic composition. The analysis by TLC shows a preliminary chemist profile of the BS (Fig. 2a). The extracts were loaded on TLC, the numbers correspond to codes (Table 2) and correspond to surfactin. The TLC revealed with UVA $366 \mathrm{~nm}$ shows that all BS have different spots. Surfactin has a RF (Retardation Factor) $=0.84$, the five BS have spots with $\mathrm{RF}$ in an interval of (0.78-0.89) (Fig. 2b). 

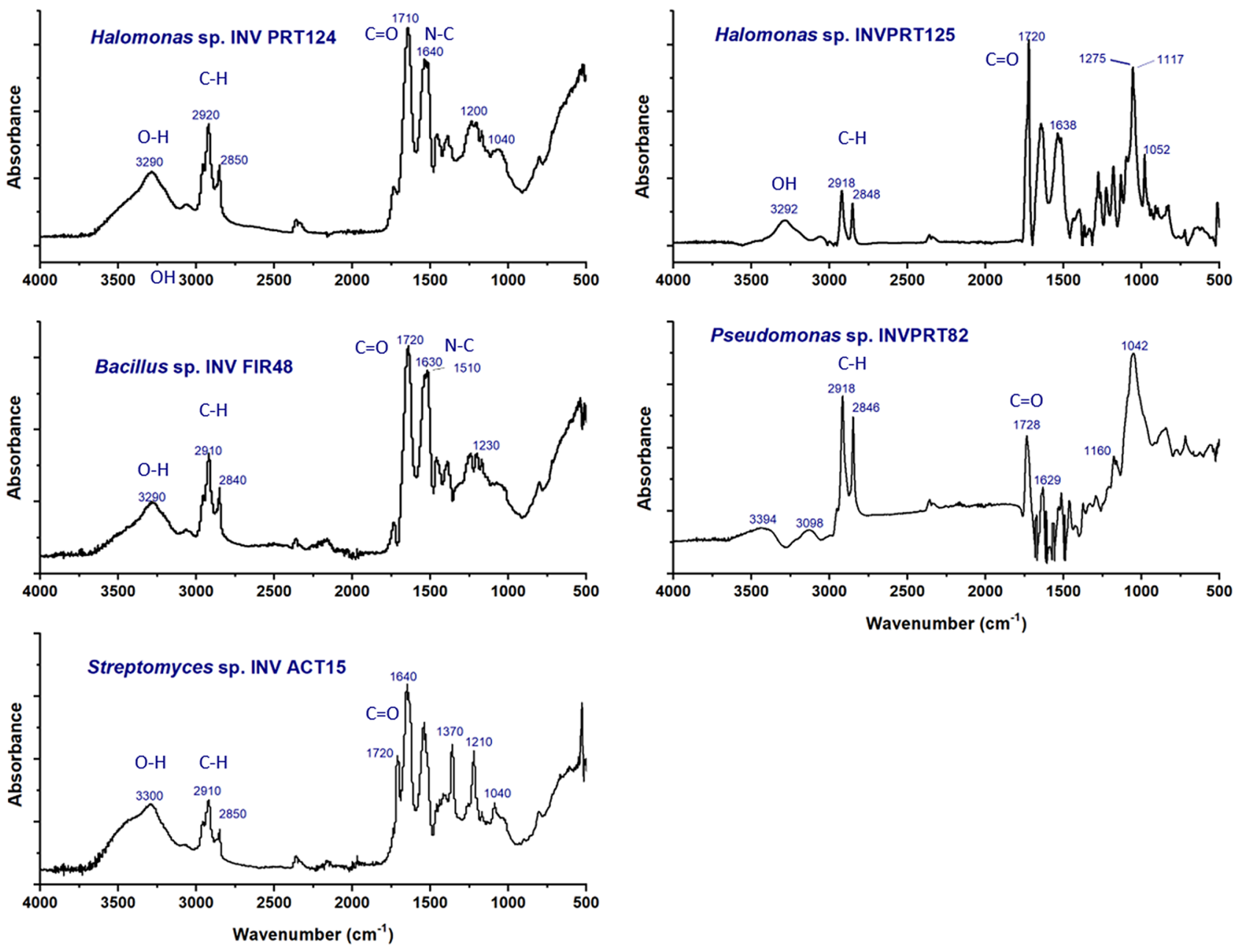

Figure 3. FT-IR spectra of biosurfactants extracts Halomonas sp. INV PRT124, Halomonas sp. INV PRT125, Bacillus sp. INV FIR48, Pseudomonas sp. INV PRT82 and Streptomyces sp. INV ACT15.

Biosurfactant characterization. FT-IR spectrum. The spectra of biosurfactants (Fig. 3) show common bands. The bands observed at wavenumber 3394, 3292 and $3290 \mathrm{~cm}^{-1}$ were attributed to stretching OH group. The absorbance bands ranging from 2920 to $2840 \mathrm{~cm}^{-1}$ correspond to the stretching vibration of C-H. The absorbance peaks in 1710,1720 and $1720 \mathrm{~cm}^{-1}$ were assigned to stretching $\mathrm{C}=\mathrm{O}$ in esters groups, probably amides. The bands showed between $1640-1629 \mathrm{~cm}^{-1}$ were attributed to flexion $\mathrm{N}-\mathrm{C}$, this result confirms the presence of peptides. The absorption peaks, located at 1160, 1052, 1042 and $1040 \mathrm{~cm}^{-1}$ showed the presence of ester carbonyl groups (-CO bond) (Table S1).

Tentative identification of compounds by HPLC-MSMS. The BS were analyzed by liquid chromatography coupled to mass spectrometry; the total ion chromatograms (TICs) for each bacterium are shown in Fig. 4 . In general, each species studied have a TIC with a huge number of peaks, the identification of compounds in mix in this case would not be successful due to the complexity of the TICs. It would be necessary to use a dereplication technique. The major number of peaks with higher intensity are between 10.0-12.0 min and 18.0-22.0 min. In the last interval, interesting peaks are detected with mass ionization $[\mathrm{M}+\mathrm{H}]^{+}$values of $1030.64 \mathrm{~m} / \mathrm{z}, 1044.56 \mathrm{~m} / \mathrm{z}$, and $1058.67 \mathrm{~m} / \mathrm{z}$.

The raw data was processed in the software MZmine, the files were uploaded online to workflow GNPS: Global Natural Products Social Molecular Networking. GNPS is a mass spectrometry data base which facilitates the identification and discovery of compounds. The dereplication was done and the results are found in the next link https:/gnps.ucsd.edu/ProteoSAFe/result.jsp?task=65fc168c2e01456d8a94a4ef086c4be0\&view=group_by_compo und. This would be the first proposal for a tentative identification of compounds existing in each biosurfactant, these results are shown in Table 3.

Thus, twenty-one compounds were identified with GNPS database, but the compounds that had a $\mathrm{m} / \mathrm{z}$ error under to $6.0 \mathrm{ppm}$ were considered in the putative identification ${ }^{8}$. The mass error compound represents the difference between observed experimental fragment $\mathrm{m} / \mathrm{z}$ and theoretical fragment $\mathrm{m} / \mathrm{z}$ reported in the database for each specific compound, so that parameter could be considered as the first criterion of identification also their MS/MS spectra was compared with the reported in the database (GNPS) ${ }^{9}$ (Figures S5-S10). 

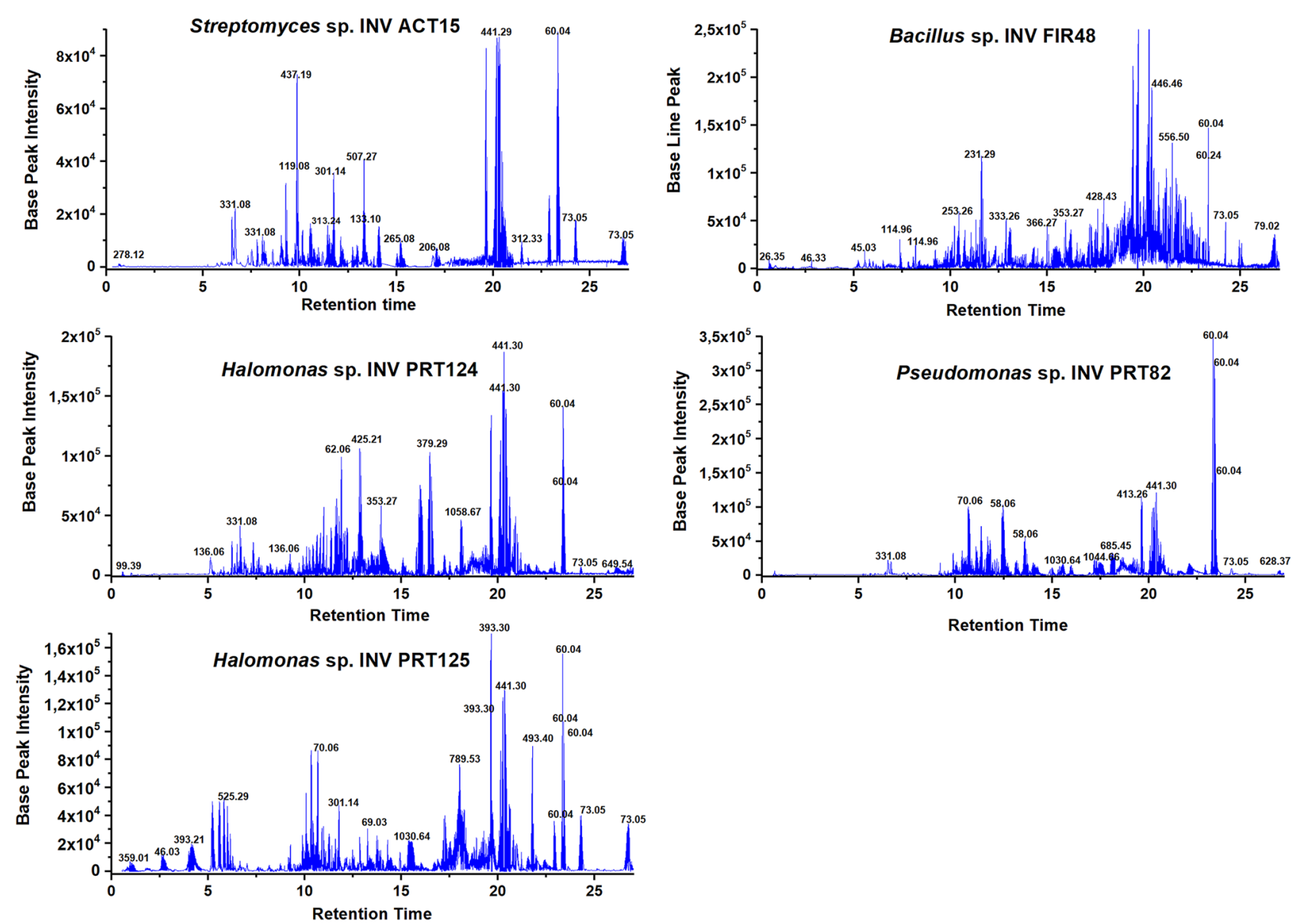

Figure 4. Chromatography profile UHPLC-MS/MS of biosurfactants extracts Halomonas sp. INV PRT124, Halomonas sp. INV PRT125, Bacillus sp. INV FIR48, Pseudomonas sp. INV PRT82 and Streptomyces sp. INV ACT15.

\begin{tabular}{|l|l|l|l|l|l|l|l|}
\hline No & Compound & MZ error PPM & M/Z & INV FIR48 & INV PRT82 & INV PRT124 & INV PRT125 \\
\hline 1 & Esperin & 1 & 1036.69 & $\checkmark$ & $\checkmark$ & $\checkmark$ & $\checkmark$ \\
\hline 2 & $\begin{array}{l}\text { [Leu7]surfactin C14i monomethyl } \\
\text { ester }\end{array}$ & 1 & 1036.69 & $\checkmark$ & & & $\checkmark$ \\
\hline 3 & Surfactin A C14 & 3 & 1022.68 & $\checkmark$ & $\checkmark$ & $\checkmark$ & \\
\hline 4 & Surfactin-D & 3 & 1050.71 & $\checkmark$ & $\checkmark$ & $\checkmark$ & \\
\hline 5 & Plipastatin & 6 & 731.39 & & $\checkmark$ & & $\checkmark$ \\
\hline 6 & [Val7]Surfactin C15ai & 4 & 1022.68 & & $\checkmark$ & $\checkmark$ & $\checkmark$ \\
\hline
\end{tabular}

Table 3. Compounds indentified putatively in biosurfactants extracts from strains Halomonas sp. INV PRT124, Halomonas sp. INV PRT125, Bacillus sp. INV FIR48 and Pseudomonas sp. INV PRT82 by dereplication tool GNPS.

Molecular networking analysis. The metabolic analysis of the five biosurfactants from bacteria was done through molecular networking with the data processed of UHPLC-MS/MS. Molecular networking was designed online in the platform GNPS and the results are available in https:/gnps.ucsd.edu/ProteoSAFe/status.jsp?task= $65 \mathrm{fc} 168 \mathrm{c} 2 \mathrm{e} 01456 \mathrm{~d} 8 \mathrm{a} 94 \mathrm{a} 4 \mathrm{ef} 086 \mathrm{c} 4 \mathrm{be} 0$. The global molecular network (GMN) of the five BS is composed by 315 nodes, which were grouped into 25 clusters, it also showed that several clusters identify some compounds as 1-(9Z-Octadecenoyl)-sn-glycero-3-phosphocholine, 1-Stearoyl-2-hydroxy-sn-glycero-3-phosphoethanolamine esperin, plipastatin and surfactin.

The molecular network of the surfactin family (Fig. 5) has 16 nodes of different colors related to their molecular weight and identification of the compounds. The nodes are connected between them, the relation is because they have the same precursor ions and some similarity in the fragmentation. Thus, it is possible to relate and identify the different isoforms of surfactin. Those were identified by dereplication with GNPS spectra libraries. 


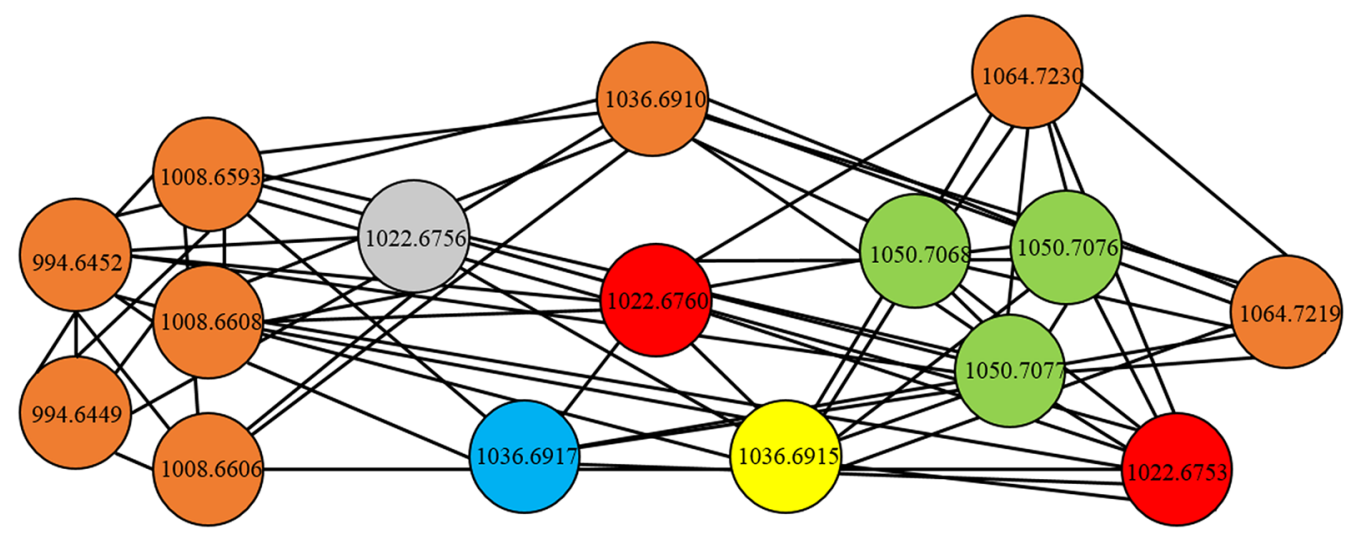

Surfactin A

Surfactin D

Surfactin monoethyl ester

[Val]Surfactin

Esperin

Surfactin isoform

Figure 5. Molecular network of the molecular family of surfactins extracted from global molecular network of biosurfactants extracts Halomonas sp. INV PRT124, Halomonas sp. INV PRT125, Bacillus sp. INV FIR48 and Pseudomonas sp. INV PRT82.

\begin{tabular}{|l|l|l|}
\hline No. catalogue MMNHC strains & IC $_{50}$ MRSA ATCC $43300\left(\mathbf{m g ~ L}^{-1}\right)$ & IC $_{50}$ C. albicans ATCC $10231\left(\mathbf{m g ~ L}^{-1}\right)$ \\
\hline $\begin{array}{l}\text { Halomonas sp. } \\
\text { INV PRT124 }\end{array}$ & $>500$ & 8.92 \\
\hline $\begin{array}{l}\text { Halomonas sp. } \\
\text { INV PRT125 }\end{array}$ & 93.48 & 7.27 \\
\hline $\begin{array}{l}\text { Bacillus sp. } \\
\text { INV FIR48 }\end{array}$ & 25.65 & 21.54 \\
\hline $\begin{array}{l}\text { Streptomyces sp. } \\
\text { INV ACT15 }\end{array}$ & $>500$ & 20.94 \\
\hline Antibiotics & 0.01 & N/A \\
\hline Rifampicin & N/A & 0.36 \\
\hline Nystatin & \multicolumn{2}{|l|}{} \\
\hline
\end{tabular}

Table 4. BSE values of Half-maximal inhibitory concentration $\left(\mathrm{IC}_{50}\right)$ for strains Halomonas sp. INV PRT124, Halomonas sp. INV PRT125, Bacillus sp. INV FIR48, Pseudomonas sp. INV PRT82 and Streptomyces sp. INV ACT15. N/A not apply.

The nodes of orange color were not possible to identify by GNPS. The value of molecular weight and connection with other surfactin isoforms infer that are isoforms too.

Antimicrobial activity. The BS presented antimicrobial activity against both pathogens with MIC values from 187.5 to $500 \mathrm{mg} \mathrm{L}^{-1}$ onwards. Bacillus sp. INV FIR48 has the higher activity against MRSA, with a MIC value of $500 \mathrm{mg} \mathrm{L}^{-1}$ that inhibited $83.7 \%$ of the pathogen. C. albicans ATCC 10231 was inhibited in $90.2 \%$ by the BS from Halomonas sp. INV PRT125, with a MIC value of more than $187.5 \mathrm{mg} \mathrm{L}^{-1}$, followed by Halomonas sp. INV PRT124 with a MIC value of more than $375 \mathrm{mg} \mathrm{L}^{-1}$, concentration that inhibited $90.3 \%$ of the yeast. Bacillus sp. INV FIR48 (MIC value of more than $375 \mathrm{mg} \mathrm{L}^{-1}$ ) and Streptomyces sp. INV ACT15 (MIC value of more than $500 \mathrm{mg} \mathrm{L}^{-1}$ ) inhibited C. albicans in $89 \%$. Pseudomonas sp. INV PRT82 showed inhibition of less than $20 \%$ at the higher concentration evaluated of $500 \mathrm{mg} \mathrm{L}^{-1}$, like the results obtained against MRSA for BS from Halomonas sp. INV PRT124 and Streptomyces sp. INV ACT15.

Therefore, the half-maximal inhibitory concentration $\left(\mathrm{IC}_{50}\right)$ of $\mathrm{BS}$ is shown in Table 4 . The inhibition values against $C$. albicans exhibit that the most effective BS was from Halomonas sp. INV PRT125 which revealed an $\mathrm{IC}_{50}$ of $7.27 \mathrm{mg} \mathrm{L}^{-1}$. Also, Halomonas sp. INV PRT124 extract express an $\mathrm{IC}_{50}$ of $8.92 \mathrm{mg} \mathrm{L}^{-1}$. These $\mathrm{IC}_{50}$ values were 
around eight times higher than the positive control Nystatin that showed an $\mathrm{IC}_{50}$ of $0.36 \mathrm{mg} \mathrm{L}^{-1}$. For Methicillinresistant S. aureus ATCC 43300 (MRSA) the BS Bacillus sp. INV FIR48 revealed an $\mathrm{IC}_{50}$ of $25.65 \mathrm{mg} \mathrm{L}^{-1}$ and the positive control was Rifampicin $\left(\mathrm{IC}_{50}\right.$ of $\left.0.01 \mathrm{mg} \mathrm{L}^{-1}\right)$. According to results and knowing that for compounds present in the mixture the $\mathrm{IC}_{50}$ value should be below $100 \mathrm{mg} \mathrm{L}^{-1}$, all the $\mathrm{BS}$ of this study are promissory for the isolation and chemical characterization, with the objective of using them as formulation for an antiseptic agent or for pharmaceutical uses.

Toxicity of biosurfactants. The toxicity that BS presented over the aquatic model organism, brine shrimp larvae Artemia franciscana was moderate under $300 \mathrm{mg} \mathrm{L}^{-1}$, only Halomonas sp. INV PRT124 showed high toxicity at $500 \mathrm{mg} \mathrm{L}^{-1}(52.5 \%)$. In addition, none of the BS have hemolytic effect over human cells when evaluated in 2 concentrations ( $333 \mathrm{mg} \mathrm{L}^{-1}$ y $166 \mathrm{mg} \mathrm{L}^{-1}$ ), with percentages lower than $1 \%$ which lead us to think that the quantity of the active compounds is lower than the sensibility of the hemolytic assay ${ }^{10}$.

\section{Discussion}

The Caribbean Sea is a semi-enclosed basin of the western Atlantic Ocean with an average depth of $2400 \mathrm{~m}$ being a $75 \%$ deeper than $1800 \mathrm{~m}$ approximately ${ }^{11}$. Worldwide, significant efforts have been made to cultivate marine microorganisms from deep-sea environments under controlled laboratory conditions obtaining a low representation of these. Nevertheless, the few representatives available are highly valuable for discovering information about unusual types of metabolism ${ }^{12}$. In marine ecosystems, the bacterial production of amphiphilic surface active molecules like biosurfactants can be involved in the microbial competition (antimicrobial properties), nutrition (favoring the accession to water-insoluble substrates) and survival ${ }^{13}$.

Bacterial growth was noted in the presence of hydrocarbon (diesel fuel) as the only carbon source, which suggests the possibility of the production of biosurfactants or other metabolites that help with the digestion of the mentioned carbon source $\mathrm{e}^{14}$. This feature makes them candidates for biodegrading contaminated sources, being this an emerging technology ${ }^{15}$. Exploring these biological processes for petroleum biotechnology and other potential applications of these biomolecules due to their biodegradability, allowed them to be used in the cosmetic and pharmaceutical fields ${ }^{16}$.

TLC analysis shows RF values close to surfactin that could indicate its presence or of analogues. Lane 1 and 2 have a similar profile, probably because strains belong to the same genus (Halomonas) and produce similar metabolites ${ }^{17}$. The purple and yellow spots correspond to the reaction of amino acids (AA) with ninhydrin. Purple corresponds to non-polar AA like glycine, alanine, valine, leucine. The yellow spots correspond to polar or negatively charged AA such as proline, asparagine, glutamine. AA are present in surfactin and iturin structure ${ }^{18}$.

The set of bands suggest the presence of the lipopeptides in all extracts ${ }^{19}$. There is a high correlation between Halomonas sp. INV PRT124 and Bacillus sp. INV FIR48 in their IR profiles. However, for Halomonas sp. INV PRT125 there are signals close to $1117 \mathrm{~cm}^{-1}$ corresponding to stretching C-O-C bonds of structures with lipopeptide character, and for Pseudomonas sp. INV PRT82 there is a strong signal found at $1042 \mathrm{~cm}^{-1}$ involving probably ester linkages of surfactin-C14 and surfactin-C15 ${ }^{20}$.

The analysis of the TICs of BS allowed to identify which peaks were common between bacteria, the most intense and selecting the interesting peaks to analyze their $\mathrm{MS}^{2}$ fragmentation or also analyzing the $\mathrm{MS}^{2}$ data with a software of data processing. The peaks with $\mathrm{m} / \mathrm{z}$ value of $1030.64 \mathrm{~m} / \mathrm{z}, 1044.56 \mathrm{~m} / \mathrm{z}$ corresponds to characteristic peaks of surfactin families ${ }^{21}$ and the peak $1058.67 \mathrm{~m} / \mathrm{z}$ corresponds to iturin (lipopeptide) ${ }^{22}$. The other compounds were identified although data was processed in MZmine and using database from GNPS (Table 3). It was possible to find common compounds in all strains, these belong to surfactin family and were identified in the strains INV FIR48, INV PRT82, INV PRT124 and INV PRT125, also it was identified that plipastatin compound belonged to iturin family. Surfactin and its isoforms are produced by the genera Bacillus, Pseudomonas, and Halomonas, this result could explain the biosurfactant activity in oil-spread assay using carbon source SM ${ }^{23}$, where the strains of Streptomyces did not produce surfactin, explaining the low activity in the same assay.

The strains studied produce different surfactin isoforms, but the strains INV PRT82 (Pseudomonas sp.) and INV PRT125 (Halomonas sp.) produce the major number of isoforms. This result could be interesting in environmental studies of bioremediation. The metabolomic study of the surfactin isoforms brings results to the diversity of metabolic of marine bacteria producer of biosurfactants.

The unknown surfactin isoforms were identified through their molecular weight, mass spectra report in literature and connections of the nodes in the molecular network (Table 5). For example, the isoform $1064.723 \mathrm{~m} / \mathrm{z}$ has a mass spectrum with characteristic peaks of surfactin (fatty acid chains). The analysis of MS ${ }^{2}$ (Figure S17) shows a loss weight of 113.0 that corresponds to leucine, a loss of 133.0 assigned to aspartate, a loss of 117.0 belonging to valine, other loss of 113.0 that also corresponds to leucine. These fragments are characteristic of surfactin A. The node of this isoform has a connection with surfactin A and its molecular weight match with surfactin A C17 ${ }^{23,24}$. Thus, the unknown surfactin isoforms were identified putatively in that way.

These results support the production of secondary metabolites with antimicrobial activity. According to the metabolic analysis, Halomonas sp. INV PRT125 produces a wide range of biosurfactants like surfactin A C14, surfactin-D, [Leu7]surfactin monoethyl ester C14, [Val7] surfactin C15 and esperin. Similarly, Halomonas sp. INV PRT124, Pseudomonas sp. INV PRT82 and Bacillus sp. INV FIR48 produced surfactin isoforms in common. It should be because most of the reports on surfactin obtention refer to genus Bacillus as its main producer ${ }^{25}$. However, there are few studies describing the production of lipopeptide families by Gram-negative bacteria and only production has been presented in bacteria isolated from soil samples of the genera Enterobacter, Citrobacter and Pseudomonas ${ }^{26,27}$. Therefore, the surfactin isoforms production by the genera Halomonas and Pseudomonas are interesting for the discovery of other producing strains, especially for isolation of marine biosurfactants, 


\begin{tabular}{|l|l|l|l|l|l|l|}
\hline Structure & Molecular formula & {$[\mathbf{M}+\mathrm{H}]^{+}$} & INV FIR48 & INV PRT82 & INV PRT124 & INV PRT125 \\
\hline [Val7]Surfactin C13 & $\mathrm{C}_{50} \mathrm{H}_{87} \mathrm{~N}_{7} \mathrm{O}_{13}$ & 994.6452 & $\checkmark$ & & & $\checkmark$ \\
\hline Surfactin C12 & $\mathrm{C}_{50} \mathrm{H}_{87} \mathrm{~N}_{7} \mathrm{O}_{13}$ & 994.6449 & $\checkmark$ & & & $\checkmark$ \\
\hline Surfactin A C13 & $\mathrm{C}_{51} \mathrm{H}_{89} \mathrm{~N}_{7} \mathrm{O}_{13}$ & 1008.6593 & & $\checkmark$ & & $\checkmark$ \\
\hline Surfactin C15 & $\mathrm{C}_{51} \mathrm{H}_{89} \mathrm{~N}_{7} \mathrm{O}_{13}$ & 1008.6608 & $\checkmark$ & & $\checkmark$ & $\checkmark$ \\
\hline Surfactin A C13 & $\mathrm{C}_{51} \mathrm{H}_{89} \mathrm{~N}_{7} \mathrm{O}_{13}$ & 1008.6606 & & $\checkmark$ & & $\checkmark$ \\
\hline Surfactin B C16 & $\mathrm{C}_{53} \mathrm{H}_{93} \mathrm{~N}_{7} \mathrm{O}_{13}$ & 1036.6910 & & $\checkmark$ & & $\checkmark$ \\
\hline Surfactin A C17 & $\mathrm{C}_{55} \mathrm{H}_{97} \mathrm{~N}_{7} \mathrm{O}_{13}$ & 1064.7230 & $\checkmark$ & $\checkmark$ & & $\checkmark$ \\
\hline Surfactin monoethyl ester C16 & $\mathrm{C}_{55} \mathrm{H}_{97} \mathrm{~N}_{7} \mathrm{O}_{13}$ & 1064.7219 & & $\checkmark$ & & $\checkmark$ \\
\hline
\end{tabular}

Table 5. Surfactin isoforms identified through molecular networking in deep-sea marine bacteria Halomonas sp. INV PRT124, Halomonas sp. INV PRT125, Bacillus sp. INV FIR48 and Pseudomonas sp. INV PRT82.

which have not been widely explored ${ }^{28}$. In this sense, the extreme environments as deep-sea, can be an important source for the isolation of new biosurfactant-producing microorganisms.

The antimicrobial activity of Surfactin A C14 obtained from marine species of genus Bacillus and evaluated against C. albicans has been studied ${ }^{1}$ reporting an anti-fungal MIC values of C14-surfactin of more than $100 \mathrm{mg}$ $\mathrm{L}^{-1}$. In our study, the BS from Bacillus sp. INV FIR48 exhibited $\mathrm{IC}_{50}$ values of $21.54 \mathrm{mg} \mathrm{L}^{-1}$ (MIC of more than $375 \mathrm{mg} \mathrm{L}^{-1}$ ), this effective concentration (below $100 \mathrm{mg} \mathrm{L}^{-1}$ ) shows the antimicrobial potential of deep-sea bacteria. Additionally, these observations of MIC values, may have proximity to that found in BS of Halomonas sp. INV PRT124 and Halomonas sp. INV PRT125 against the yeast C. albicans ATCC 10231. It is known the surfactin to interact with the cell membrane and disturb the membrane's stability ${ }^{29}$, hence the novelty production of surfactin A C14 by species of genus Halomonas is promising for further exploration of other biological activities.

On the other hand, Bacillus sp. INV FIR48 and Halomonas sp. INV PRT125 showed antimicrobial activity against MRSA. It is interesting for the study that strains belonging to different bacterial genera produced surfactin isoforms in common, like Surfactin A C14, Surfactin D and [Leu7] surfactin monoethyl ester C14. Liu reports the ability of surfactin produced by Bacillus subtilis for affecting S. aureus biofilm formation, also the lipopeptide attacks the quorum sensing (QS) system in the Gram-positive bacteria S. aureus ${ }^{30}$. In general, the Gram-positive bacteria are considered more sensitive to natural compounds due to the structure of their cell walls, the lipopeptides pore formation in membranes, leading to an imbalance in transmembrane ion fluxes and cell death ${ }^{31}$.

The BS toxicity was evaluated using Artemia franciscana and a hemolytic assay. Brine shrimp, Artemia spp., is an invertebrate zooplankton involved in the energy flow of the food chain in many of saltwater lake ecosystems. Due to its high offspring production and ease of culture, short life cycle, ready availability, and small body size, this aquatic invertebrate is widely used in toxicity assays ${ }^{32}$. On the other hand, the term hemolysis refers to the phenomenon of rupture or lysis of the erythrocyte membrane due to the action of physical or chemical agents causing the release of hemoglobin. In the body, hemolysis causes oxygen deficiency in the tissues, release of reticulocytes into the bloodstream and physical wear and tear of the bone marrow. The hemolysis test is very useful when it comes to obtaining possible compounds or drug candidates, since in many cases blood is one of the transport frontiers of these molecules ${ }^{33}$.

Studies showed that surfactin isoforms, like C14 and C15, from Bacillus subtilis are thought to be related to antimicrobial activity ${ }^{34}$. Also, the authors notice that hemolytic activity increased within higher hydrophobicity of the compound, but other investigations ${ }^{35}$ revealed the opposite, that the hemolytic activity of synthetic surfactin analogues is not related to their hydrophobicity.

Lastly, in our study was found that the deep-sea bacteria produced more than one biosurfactant and it is necessary the purification to confirm that antimicrobial activity is due to surfactin. Furthermore, the novelty of production of surfactin isoforms by genus Halomonas and Pseudomonas is promising as new source of marine biosurfactants to continue exploring other possible specific biological activities. The activity against Methicillinresistant S. aureus and C. albicans, non-ecotoxicity against Artemia franciscana neither toxicity over human red blood cells, shows promising results for further investigation.

\section{Materials and methods}

Culture medium. Marine agar (Difco), Bushnell-Haas broth modified (magnesium sulphate (0.2\%), calcium chloride $(0.02 \%)$, monopotassium phosphate $(1.0 \%)$, dipotassium phosphate $(1.0 \%)$, sodium nitrate $(1.0 \%)$, ferric chloride (0.05\%)) and supplemented with Sugarcane molasses (SM) (1.0\%), TSA and Muller-Hinton broth.

Bacteria isolation, culture, and molecular identification. Deep-sea bacteria were isolated from sediments samples obtained from the exploration blocks in Colombian Caribbean Sea, denominated as COL1

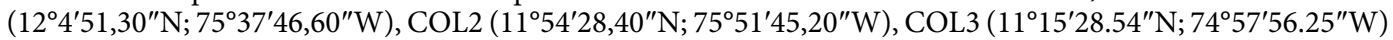
and COL10 $\left(14^{\circ} 11^{\prime} 23.76^{\prime \prime} \mathrm{N} ; 7^{\circ} 13^{\prime} 2.81^{\prime \prime} \mathrm{W}\right)$, in the sampling stations E466 at $3328 \mathrm{~m}, \mathrm{E} 428$ at $3186 \mathrm{~m}, \mathrm{E} 556$ at $818 \mathrm{~m}$ and E603 at $3474 \mathrm{~m}$, respectively. All of the 378 bacterial strains isolated from these stations were screened to notice their biosurfactant production ${ }^{36}$. For molecular identification, the $16 \mathrm{~S}$ rRNA gene was amplified using the following prokaryotic universal primers: F (5'-AGA GTT TGA TCC TGG CTG AG-3') and R (5'-GGT TAC CTT GTT ACG ACT T-3' $)^{37,38}$. The 16S RNA gene was sequenced in CNSG and Corpogen-Colombia. The identity of the sequences was compared with reference taxonomies hosted by SILVA (RDP, Greengenes, and 
SILVA $)^{39-41}$ using the least common ancestor (LCA) method and searching five of the nearest sequences with a similarity superior at 97\% (Figures S1, S2 and S3) and sequences were deposited in GenBank (Table 1). Therefore, Halomonas sp. INV PTR124, Halomonas sp. INV PTR125, Bacillus sp. INV FIR48, Pseudomonas sp. INV PRT82 and Streptomyces sp. INV ACT15 were the strains used in this study for biosurfactant producing bacteria. The set of bacteria was deposited at the Marine Museum of Natural History of Colombia-Makuriwa (MMNHC).

Bushnell-Haas broth modified with $1 \%$ sodium chloride and $1 \%$ Diesel fuel (DF) as carbon source were used as production medium for the culture of microorganisms. One or two colonies were suspended in $10 \mathrm{~mL}$ of medium until $0.5 \mathrm{McF}$ arland scale, aliquots of $1 \mathrm{~mL}$ were used for inoculated $25 \mathrm{~mL}$ of production medium. After 7 days of incubation at $30^{\circ} \mathrm{C}$ and $140 \mathrm{rpm}, 1 \mathrm{~mL}$ of the cell-free culture was obtained by centrifugation at $9520 \mathrm{~g}$, for $10 \mathrm{~min}$ at room temperature.

Oil-spreading (OS) test of biosurfactants. In a petri dish containing $40 \mathrm{~mL}$ of distilled water, $20 \mu \mathrm{L}$ of crude oil were poured in a thin layer on the surface. Then $20 \mu \mathrm{L}$ of cell-free culture were added carefully in the center of the layer, the diameter of spreading was measured in $\mathrm{mm}$. As negative control, $20 \mu \mathrm{L}$ of the broth without inoculum was used, and $20 \mu \mathrm{L}$ of neutral detergent (Extran MA 02) as positive control of displacement, each one in different petri dishes. The assay was done by triplicate.

A positive result was the spreading of the crude oil and a zone of emulsification on the surface ${ }^{42}$. Microorganisms that had positive results were cultured in Bushnell-Haas broth modified now with $1 \%$ sugarcane molasses (SM), to evaluate the production of metabolites in different carbon sources like this agro-industrial waste.

Extraction of biosurfactants. The cells were removed by centrifugation at $2705 \mathrm{~g}$ for $20 \mathrm{~min}$ at $4{ }^{\circ} \mathrm{C}$. The $\mathrm{pH}$ was adjusted to 2.0 with $6 \mathrm{M} \mathrm{HCl}$, and the supernatant was incubated overnight at $4^{\circ} \mathrm{C}$ to improve the precipitation. The precipitate was then collected by centrifugation at $2705 \mathrm{~g}$ for $30 \mathrm{~min}$ at $4{ }^{\circ} \mathrm{C}$. Those were washed with $\mathrm{HCl} 0.1 \mathrm{M}$ and suspended in water, its $\mathrm{pH}$ was adjusted 8.0, this suspension was freeze-dried. Finally, the BS were extracted with a mix chloroform: methanol $(65: 15)$ and evaporated under reduced pressure in a rotary evaporator at $40^{\circ} \mathrm{C}^{24}$. The $\mathrm{BS}$ were weighted, and the production was calculated.

Characterization of biosurfactants. Chromatography TLC plates analysis. The biosurfactants and surfactin were dissolved in a chloroform: methanol (13:3) mixture and subjected to thin layer chromatography (TLC) Silica Gel 60 F254, this was carried out in the mobile phase of the same mixture. The spots were revealed under UVA radiation $(366 \mathrm{~nm})$. Then the plates were immersed in a solution to $0.5 \%$ of ninhydrin/methanol for $10 \mathrm{~s}$ and heated to $100{ }^{\circ} \mathrm{C}$ for $1 \mathrm{~h}^{43}$.

Spectroscopy FT-IR analysis. The spectrums of attenuated total reflectance (ATR) were obtained using a FTIR spectrophotometer IR Tracer-100 (Shimadzu), with a detector DLATS and a horizontal reflection accessory ATR (ATR-MIRacle PIKE). Each spectrum was run with an average of 64 scans and with a resolution of $8 \mathrm{~cm}^{-144}$. The signal assignment was performed considering the table of infrared spectroscopy of Sigma Aldrich ${ }^{45}$.

Liquid chromatography-MS/MS (LC-MS/MS) analyses. LC-MS/MS was performed in a UHPLC Thermo Dionex Ultimate 3000 coupled with HRMS (Impact II, Bruker Daltonics Corporation, USA) equipped with an electrospray ionization source (ESI). The chromatography system used an analytic column C18 (LC column Kinetex $1.7 \mu \mathrm{m}$ particle size, $100 \times 2.1 \mathrm{~mm}$ ). The mobile phase is a binary solvent system consisting of A (water, $0.1 \% \mathrm{FA})$ and B (ACN, $0.1 \% \mathrm{FA})$. The elution conditions were "discontinuous" gradient as follows: $10 \% \mathrm{~B}$ for $5 \mathrm{~min}, 10-70 \%$ B over $7 \mathrm{~min}, 70 \%$ B for $5 \mathrm{~min}, 70-99 \%$ B over $4 \mathrm{~min}$ and $99 \%$ B for $6 \mathrm{~min}$. The injection volume was $1 \mu \mathrm{L}$, the flow rate of $0.4 \mathrm{~mL} / \mathrm{min}$. Ionizations were acquired in positive ion mode using electrospray ionization mass spectrometry (ESI-MS) with capillary temperature, and the voltage was set at $200{ }^{\circ} \mathrm{C}, 3.5 \mathrm{kV}$, respectively. The scan ranged from $\mathrm{m} / \mathrm{z} 50$ to 1200 . The obtained data were processed by Compass DataAnalysis software (Bruker) ${ }^{46}$.

MS/MS data processing to molecular networking. Raw data from UHPLC-MS/MS analysis were converted to. mzXML format with Bruker's Compass DataAnalysis software. LC-MS data was then preprocessed with the open-source software MZmine and consisted of peak detection, isotopes removal, peak matching, and peak filling. Peak detection was performed in three steps: (1st) mass detection with noise value $=500$; (2nd) chromatogram builder with minimum time span $=0.01 \mathrm{~min}$, minimum height $=3000$ and $\mathrm{m} / \mathrm{z}$ tolerance $=5.0 \mathrm{ppm} ;(=3 \mathrm{rd})$ deconvolution with peak width $=0.01-0.5 \mathrm{~min}$, noise $=5000$. Isotopes were removed using the isotopic peak grouper with $\mathrm{m} / \mathrm{z}$ tolerance $=5.0 \mathrm{ppm}$, retention time tolerance $=0.1 \mathrm{~min}$ and minimum standard intensity $=5000$. Then, a filter was applied to keep only those ions with at least 2 peaks in their isotope pattern. Peak matching among samples was performed using the join aligner with $\mathrm{m} / \mathrm{z}$ tolerance $=5.0 \mathrm{ppm}^{47}$. The final step was to export two files in format .mgf and .CSV, both files were uploaded to the global natural product social (GNPS) molecular networking tools ${ }^{48}$.

Finally, the maximum size of a molecular family was set to 100 , and the lowest scoring edges were removed from molecular families until the molecular family size was below this threshold. The spectra in the network were then searched against GNPS spectral libraries ${ }^{48,49}$.The molecular networks were visualized using software Cytoscape version 3.7.2.

Antimicrobial assays. Broth microdilution test. Antimicrobial activity evaluation of BS was performed according to the methodology described by Quintero ${ }^{50}$. Biosurfactants were suspended in $2 \%$ DMSO and con- 
centration values from 6.25 to $500 \mu \mathrm{g} \mathrm{mL} \mathrm{m}^{-1}$ were evaluated through broth microdilution test as recommended by $\mathrm{CLSI}^{51}$. It was carried out in 96-well microplate (Corning F-bottom) by triplicate, against two pathogenic microorganisms: Gram-positive, round-shape bacteria Methicillin-resistant Staphylococcus aureus subsp. aureus ATCC 43300 (MRSA), and the opportunistic pathogenic yeast Candida albicans ATCC 10231. Each pathogenic strain in exponential growth phase was suspended in $10 \mathrm{~mL}$ of sterile Mueller-Hinton broth until obtaining 0.5 McFarland scale concentrations $\left(10^{8} \mathrm{CFU} \mathrm{mL} \mathrm{m}^{-1}\right)$, then they were exposed to the BS. Same suspension of pathogens was used as grown control and antibiotics (Rifampicin and Nystatin) were used as inhibition control. The plates were incubated at $30^{\circ} \mathrm{C}$ for $24 \mathrm{~h}$ and the optical density (OD) was measured at $600 \mathrm{~nm}$ in the Multiskan GO spectrophotometer (Thermo Scientific). The inhibition and growth percentage were obtained by the following equations:

$$
\begin{gathered}
\% \text { Growth }=\frac{\left(O D_{\text {Treatment }}-O D_{\text {Blank }}\right)}{O D_{\text {Positive control }}} \times 100 \\
\% \text { Inhibition }=100-\% \text { Growth }
\end{gathered}
$$

The half- maximal inhibitory concentration $\left(\mathrm{IC}_{50}\right)$ was calculated in accordance with the Clinical laboratory Standards Institute (CLSI) standard procedure for in vitro antimicrobial susceptibility testing ${ }^{52}$.

Toxicology assays. Short-term lethal toxicity test with brine shrimp larvae. Ecotoxicity of the BS were measured adjusting the method of brine shrimp lethality test by Rajabi ${ }^{53}$, for Brine shrimp larvae. Dried cysts were cultured $48 \mathrm{~h}$ before in artificial sea water $35 \mathrm{ppt}$ at room temperature $\left(25-30{ }^{\circ} \mathrm{C}\right)$ under aeration and continuous illumination (2000 LUX), only the larvae (nauplii) hatched were selected for the assay.

The BS ecotoxicity was evaluated within concentration values from 150 to $500\left(\mathrm{mg} \mathrm{L}^{-1}\right)$ in 96 -well microplates. BS were solved in 1.5\% Methanol. Each well containing 10 nauplii in $200 \mu \mathrm{L}$ of artificial sea water and the correspondent concentrations were poured by quadruplicate, water was used as negative control, copper sulfate $\left(\mathrm{CuSO}_{4} \cdot 5 \mathrm{H}_{2} \mathrm{O}\right)$ as positive control and $1.5 \%$ Methanol as solvent control. The plate was incubated for $24 \mathrm{~h}$ under illumination, the surviving organisms were counted for each well under a stereomicroscope (Carl Zeiss STeREO Discovery V.8). Lethality percentage was calculated and ecotoxicity was determined with this scale: $0-10 \%$ Nontoxic, $11-50 \%$ lowly toxic, $51-90 \%$ highly toxic and $100 \%$ extremely toxic ${ }^{54}$.

Hemolysis assay. This study was made according to resolution No. 008430 of 1993 of the Ministry of Health of Colombia ${ }^{55}$. All methods were performed in accordance with the ethical guidelines and regulations, and informed consent was obtained from the participating individual. Primary culture of human cells was obtained from blood of a healthy volunteer, according to ${ }^{56}$ modified method. The erythrocytes were collected from peripheral human blood (A positive) in vacutainer $\mathrm{K}_{2}$ EDTA tube (BD) by centrifugation at $2705 \mathrm{~g}$ for $5 \mathrm{~min}$ at room temperature $\left(25-30^{\circ} \mathrm{C}\right)$, then 3 washes were made with 1X PBS rejecting the supernatant (or blood plasma) in each. At last, the hematocrit (pellet) was solved in 1 X PBS (1:10) which means a suspension of $5 \times 10^{8} \mathrm{~g} \mathrm{~mL}^{-1}$. $300 \mu \mathrm{L}$ of the hematocrit solution were poured in a sterile microtube and $300 \mu \mathrm{L}$ of the BS (solved in DMSO previously). The tubes were incubated for $1 \mathrm{~h}$ at $37^{\circ} \mathrm{C}$, then the tubes were centrifuged at $1350 \mathrm{~g}$ for $10 \mathrm{~min}$, and $100 \mu \mathrm{L}$ were poured in each well of the 96-well plate (by triplicate). Absorbance was measured at $541 \mathrm{~nm}$ in a Thermo Scientific Multiskan GO Microplate Spectrophotometer. The hematocrit solution without treatment was used as negative control, hematocrit solved in 1X PBS (1:10) and hematocrit in 1\% DMSO. Triton X-100 and deionized (purified) water were used as positive control. The toxicity was calculated as the relative percentage over the positive control (Triton X-100) and values $<10 \%$ were accepted $^{33}$.

Received: 8 April 2021; Accepted: 21 July 2021

Published online: 11 August 2021

\section{References}

1. Bravo, K. \& La Pereañez, J. A. biodiversidad Colombiana, una oportunidad para el fortalecimiento de las industrias farmacéutica y cosmética. Vitae 23, 163-165 (2016).

2. Tortorella, E. et al. Antibiotics from deep-sea microorganisms: Current discoveries and perspectives. Mar. Drugs 16, 355 (2018).

3. Prestinaci, F., Pezzotti, P. \& Pantosti, A. Antimicrobial resistance: A global multifaceted phenomenon. Pathogens Global Health 109, 309-318 (2015).

4. Rodríguez-Baño, J. et al. Antimicrobial resistance research in a post-pandemic world: Insights on antimicrobial resistance research in the COVID-19 pandemic. J. Glob. Antimicrob. Resist. 25, 5-7 (2021).

5. Burgess, K., Rankin, N. \& Weidt, S. Metabolomics. in Handbook of Pharmacogenomics and Stratified Medicine 181-205 (Elsevier Inc., 2014). https://doi.org/10.1016/B978-0-12-386882-4.00010-4

6. Clish, C. B. Metabolomics: an emerging but powerful tool for precision medicine. Mol. Case Stud. 1, a000588 (2015).

7. Nothias, L. F. et al. Feature-based molecular networking in the GNPS analysis environment. bioRxiv https://doi.org/10.1101/812404 (2019).

8. Mihaleva, V. V. et al. Accurate mass error correction in liquid chromatography time-of-flight mass spectrometry based metabolomics. Metabolomics 4, 171-182 (2008).

9. Nothias, L. F. et al. UCSD Computational Mass Spectrometry Website. GNPS Quickstart Molecular Networking Analysis 1-1 (2020). https://gnps.ucsd.edu/ProteoSAFe/result.jsp?task=65fc168c2e01456d8a94a4ef086c4be0\&view=group_by_compound (Accessed 25 August 2020)

10. Dufour, S. et al. Hemolytic activity of new linear surfactin analogs in relation to their physico-chemical properties. Biochim. Biophys. Acta Gen. Subj. 1726, 87-95 (2005). 
11. Hernández-Ávila, I. Patterns of deep-water coral diversity in the Caribbean Basin and adjacent southern waters: An Approach based on Records from the R/V Pillsbury Expeditions. PLOS ONE 9, e92834 (2014).

12. Orcutt, B. N., Sylvan, J. B., Knab, N. J. \& Edwards, K. J. Microbial ecology of the dark ocean above, at, and below the seafloor. Microbiol. Mol. Biol. Rev. 75, 361-422 (2011).

13. Ibacache-Quiroga, C. et al. The hydrocarbon-degrading marine bacterium Cobetia sp. strain MM1IDA2H-1 produces a biosurfactant that interferes with quorum sensing of fish pathogens by signal hijacking. Microb. Biotechnol. 6, 394-405 (2013).

14. Santos, D. K. F., Rufino, R. D., Luna, J. M., Santos, V. A. \& Sarubbo, L. A. Biosurfactants: Multifunctional biomolecules of the 21st century. Int. J. Mol. Sci. 17, 401 (2016).

15. Singh, A. \& Lin, J. Diesel degradation and biosurfactant production by Gram-positive isolates Bacterial Survival View project Green and non-toxic approaches for managing biocorrosion in oil and gas industries View project. Artic. AFRICAN J. Biotechnol. 8, 5847-5854 (2009).

16. Karlapudi, A. P. et al. Role of biosurfactants in bioremediation of oil pollution-A review. Petroleum 4, 241-249 (2018).

17. Elling, F. J. et al. Chemotaxonomic characterisation of the thaumarchaeal lipidome. Environ. Microbiol. 19, 2681-2700 (2017).

18. Piedrahíta-Aguirre, C. A. \& Alegre, R. M. Production of lipopeptide iturin a using novel strain Bacillus iso 1 in a packed bed bioreactor. Biocatal. Agric. Biotechnol. 3, 154-158 (2014).

19. Das, P., Mukherjee, S. \& Sen, R. Antimicrobial potential of a lipopeptide biosurfactant derived from a marine Bacillus circulans. J. Appl. Microbiol. 104, 1675-1684 (2008).

20. Shao, C., Liu, L., Gang, H., Yang, S. \& Mu, B. Structural diversity of the microbial surfactin derivatives from selective esterification approach. Int. J. Mol. Sci. 16, 1855-1872 (2015).

21. Ma, Y. et al. Identification of lipopeptides in Bacillus megaterium by two-step ultrafiltration and LC-ESI-MS/MS. AMB Express 6, 79 (2016).

22. Pathak, K. V. \& Keharia, H. Identification of surfactins and iturins produced by potent fungal antagonist, Bacillus subtilis K1 isolated from aerial roots of banyan (Ficus benghalensis) tree using mass spectrometry. 3 Biotech 4, 283-295 (2014).

23. Nayarisseri, A., Singh, P. \& Singh, S. K. Screening, isolation and characterization of biosurfactant producing Bacillus subtilis strain ANSKLAB03. Bioinformation 14, 304-314 (2018).

24. Moro, G. V. et al. Identification and ultra-high-performance liquid chromatography coupled with high-resolution mass spectrometry characterization of biosurfactants, including a new surfactin, isolated from oil-contaminated environments. Microb. Biotechnol. 11, 759-769 (2018).

25. Sarwar, A. et al. Qualitative analysis of biosurfactants from Bacillus species exhibiting antifungal activity. PLoS ONE 13, e0198107 (2018).

26. Nielsen, T. H. \& Sørensen, J. Production of cyclic lipopeptides by Pseudomonas fluorescens strains in bulk soil and in the sugar beet rhizosphere. Appl. Environ. Microbiol. 69, 861-868 (2003).

27. You, J., Yang, S.-Z. \& Mu, B.-Z. Structural characterization of lipopeptides from Enterobacter sp. strain N18 reveals production of surfactin homologues. Eur. J. Lipid Sci. Technol. 117, 890-898 (2015).

28. Gudiña, E. J., Teixeira, J. A. \& Rodrigues, L. R. Biosurfactants produced by marine microorganisms with therapeutic applications. Mar. Drugs 14, 38 (2016)

29. Eeman, M. et al. Penetration of surfactin into phospholipid monolayers: Nanoscale interfacial organization. Langmuir 22, 1133711345 (2006).

30. Liu, J. et al. Surfactin effectively inhibits Staphylococcus aureus adhesion and biofilm formation on surfaces. Appl. Microbiol. Biotechnol. 103, 4565-4574 (2019).

31. Raaijmakers, J. M., de Bruijn, I., Nybroe, O. \& Ongena, M. Natural functions of lipopeptides from Bacillus and Pseudomonas: More than surfactants and antibiotics. FEMS Microbiol. Rev. 34, 1037-1062 (2010).

32. Sarkheil, M. et al. Acute toxicity, uptake, and elimination of zinc oxide nanoparticles ( $\mathrm{nnO} \mathrm{NPs}$ ) using saltwater microcrustacean, Artemia franciscana. Environ. Toxicol. Pharmacol. 57, 181-188 (2018).

33. Aloisio, E. et al. Random uncertainty of photometric determination of hemolysis index on the Abbott Architect c16000 platform. Clin. Biochem. 57, 62-64 (2018).

34. Kracht, M. et al. Antiviral and hemolytic activities of surfactin isoforms and their methyl ester derivatives. J. Antibiot. (Tokyo) 52, 613-619 (1999).

35. Yuan, L., Zhang, S., Peng, J., Li, Y. \& Yang, Q. Synthetic surfactin analogues have improved anti-PEDV properties. PLoS ONE 14, e0215227 (2019).

36. Santos Acevedo, M. et al. Microvida del Caribe colombiano profundo. (INVEMAR, 2018).

37. Weisburg, W. G., Barns, S. M., Pelletier, D. A. \& Lane, D. J. 16S ribosomal DNA amplification for phylogenetic study. J. Bacteriol. 173, 697-703 (1991).

38. Yuan, M., Yu, Y., Li, H. R., Dong, N. \& Zhang, X. H. Phylogenetic diversity and biological activity of actinobacteria isolated from the chukchi shelf marine sediments in the arctic ocean. Mar. Drugs 12, 1281-1297 (2014).

39. McDonald, D. et al. An improved Greengenes taxonomy with explicit ranks for ecological and evolutionary analyses of bacteria and archaea. ISME J. 6, 610-618 (2012).

40. Quast, C. et al. The SILVA ribosomal RNA gene database project: Improved data processing and web-based tools. Nucleic Acids Res. 41, D590 (2013).

41. Cole, J. R. et al. Ribosomal database project: Data and tools for high throughput rRNA analysis. Nucleic Acids Res. 42, D633-D642 (2014).

42. Satpute, S. K. et al. Molecular genetics of biosurfactant synthesis in microorganisms. Adv. Exp. Med. Biol. 672, 14-41 (2010).

43. Alajlani, M., Shiekh, A., Hasnain, S. \& Brantner, A. Purification of bioactive lipopeptides produced by Bacillus subtilis Strain BIA. Chromatographia 79, 1527-1532 (2016).

44. Kiefer, J., Radzuan, M. \& Winterburn, J. Infrared spectroscopy for studying structure and aging effects in rhamnolipid biosurfactants. Appl. Sci. 7, 533 (2017).

45. Sigma aldrich, M. IR Spectrum Table \& Chart | Sigma-Aldrich. IR Spectrum Table \& Chart 1 (2018). https://www.sigmaaldrich. com/technical-documents/articles/biology/ir-spectrum-table.html (Accessed 23 August 2020)

46. Sudarmono, P., Wibisana, A., Listriyani, L. W. \& Sungkar, S. Characterization and synergistic antimicrobial evaluation of lipopeptides from Bacillus amyloliquefaciens isolated from oil-contaminated soil. Int. J. Microbiol. 2019 (2019).

47. Nunes, J. et al. A metabolomics-inspired strategy for the identification of protein covalent modifications. Front. Chem. 7, 532 (2019).

48. Hakeem Said, I. et al. LC-MS/MS based molecular networking approach for the identification of cocoa phenolic metabolites in human urine. Food Res. Int. 132, 109119 (2020).

49. Wang, M. et al. Sharing and community curation of mass spectrometry data with Global Natural Products Social Molecular Networking. Nat. Biotechnol. 34, 828-837 (2016).

50. Quintero, M. et al. Bioprospecting from marine coastal sediments of Colombian Caribbean: screening and study of antimicrobial activity. J. Appl. Microbiol. 125, 753-765 (2018).

51. Weinstein, M. P. et al. M100 Performance Standards for Antimicrobial Susceptibility Testing A CLSI supplement for global application. Performance Standards for Antimicrobial Susceptibility Testing Performance Standards for Antimicrobial Susceptibility Testing. (2020). 
52. Schwarz, S. et al. Editorial: Assessing the antimicrobial susceptibility of bacteria obtained from animals. J. Antimicrob. Chemother. 65, 601-604 (2010).

53. Rajabi, S., Ramazani, A., Hamidi, M. \& Naji, T. Artemia salina as a model organism in toxicity assessment of nanoparticles. DARU J. Pharm. Sci. 23, 1-6 (2015).

54. Wu, C. An important player in brine shrimp lethality bioassay: The solvent. Journal of Advanced Pharmaceutical Technology and Research 5, (Medknow Publications, 2014).

55. Ministerio de salud de Colombia. No. Resolución 008430 of 1993 of the Ministry of Health of Colombia. 1-19 (1993). https://www. minsalud.gov.co/sites/rid/Lists/BibliotecaDigital/RIDE/DE/DIJ/RESOLUCION-8430-DE-1993.PDF (Accessed 22 April 2021)

56. Pagliara, P. \& Caroppo, C. Cytotoxic and antimitotic activities in aqueous extracts of eight cyanobacterial strains isolated from the marine sponge Petrosia ficiformis. Toxicon 57, 889-896 (2011).

\section{Acknowledgements}

Thanks to the national hydrocarbons agency (ANH), the Ministerio de Medio Ambiente y Desarrollo Sostenible (MADS), the Ministerio de Ciencia, Tecnología e innovación (Minciencias) and to the Marine and Coastal Research Institute José Benito Vives de Andréis"-INVEMAR for the financial support (Contribution number CTRB-1318 - from the Evaluation and Use of Marine and Coastal Resources Program - VAR, Marine Bioprospecting Line). For publication, this research has been funded by Dirección General de Investigaciones of Universidad Santiago de Cali under call No 01-2021.

\section{Author contributions}

A.D.P. Conceptualization, Methodology, Validation, Investigation, Writing-Original Draft, Visualization; M.M. Methodology, Validation, Investigation, Writing-Original Draft, Visualization; M.Q. Methodology, Validation, Investigation, Writing-Original Draft, Data Curation; L.L.L. Formal analysis Writing-Review and Editing; L.M.B. Software, Formal analysis, Data Curation Writing-Review and Editing, Supervision; J.G. WritingReview and Editing, Supervision, Project administration.

\section{Funding}

This research was carried out within the framework of the contract (Contrato marco de acceso a recursos genéticos y sus productos derivados No. 123; Expediente RGE 0158-5 and RGE0 158-6) granted to the Marine and Coastal Research Institute José Benito Vives de Andréis -INVEMAR by the Ministerio de Ambiente y Desarrollo Sostenible de Colombia. All the experimental protocols were approved by the ethics committee of Marine and Coastal Research Institute José Benito Vives de Andréis"-INVEMAR, in the minutes No. 04-2018.

\section{Competing interests}

The authors declare no competing interests.

\section{Additional information}

Supplementary Information The online version contains supplementary material available at https://doi.org/ 10.1038/s41598-021-95788-9.

Correspondence and requests for materials should be addressed to L.M.B.

Reprints and permissions information is available at www.nature.com/reprints.

Publisher's note Springer Nature remains neutral with regard to jurisdictional claims in published maps and institutional affiliations.

Open Access This article is licensed under a Creative Commons Attribution 4.0 International License, which permits use, sharing, adaptation, distribution and reproduction in any medium or format, as long as you give appropriate credit to the original author(s) and the source, provide a link to the Creative Commons licence, and indicate if changes were made. The images or other third party material in this article are included in the article's Creative Commons licence, unless indicated otherwise in a credit line to the material. If material is not included in the article's Creative Commons licence and your intended use is not permitted by statutory regulation or exceeds the permitted use, you will need to obtain permission directly from the copyright holder. To view a copy of this licence, visit http://creativecommons.org/licenses/by/4.0/.

(C) The Author(s) 2021 